\title{
Plasmocytoid Myoepithelioma of the Upper Lip: Case Report
}

\author{
Kessab $\mathrm{A}^{1,2^{*}}$, Tbouda $\mathrm{M}^{1,2}$, Azakhmam $\mathrm{M}^{1,2}$, Oukabli $\mathrm{M}^{1,2}$ and AL Bouzidi $\mathrm{A}^{1,2}$ \\ ${ }^{1}$ Department of pathology Military hospital Mohammed V Rabat -Morocco \\ ${ }^{2}$ Faculty of Medicine and Pharmacy of Rabat (FMPR) Mohamed V. Rabat- Morocco
}

DOI: $10.36348 /$ sjpm.2020.v05i12.008

| Received: 06.12.2020 | Accepted: 16.12.2020 | Published: 20.12 .2020

*Corresponding author: Kessab A

\section{Abstract}

Myoepithelioma is a rare benign tumor of the salivary glands. We report an observation of an accessory salivary gland myoepithelioma discovered incidentally in a 36-year-old man. The clinical aspect of the lesion suggests the diagnosis of a benign tumor. Microscopic and immunohistochemical examinations confirmed the myoepithelial nature of the tumor. The diagnosis of this neoplasm remains controversial, however, due to the variable clinical and histological aspects. The prognosis is good Treatment is surgical.

Keywords: Myoepithelioma, Salivary, Lip, Histology.

Copyright $\odot 2020$ The Author(s): This is an open-access article distributed under the terms of the Creative Commons Attribution 4.0 International License (CC BY-NC 4.0) which permits unrestricted use, distribution, and reproduction in any medium for non-commercial use provided the original author and source are credited.

\section{INTRODUCTION}

Salivary myoepitheliomas are relatively rare, accounting for less than $1 \%$ of all salivary gland neoplasms. For the accessory salivary glands, their favorite site is the palate, lip localization is extremely rare [1].

Clinically this tumor can have several presentations either: a hard or sometimes cystic lesion, most often evoking the diagnosis of a pleomorphic adenoma or a basal cell adenoma or even a malignant tumor like adenoid cystic carcinoma [1].

Pathologically it is a tumor made exclusively of myoepithelial cells with the possibility of various structures: reticular, myxoid, or solid and various differentiations: plasmocytoid, monocytoid, clear cell or spindle cell [2].

\section{CASE REPORT}

Our 51 year old patient, with no particular history, who presented a cystic nodule of the left upper lip of soft consistency, painful, evolving for a year. Surgical excision was performed. At the level of our structure we received a $2.4 \times 2 \mathrm{~cm}$ fragment of graywhite appearance of soft consistency; when cut, note the presence of a greyish myxoid appearance.

The microscopic study shows a tumor proliferation of reticular architecture of plasmocytoid cells with an eccentric nucleus and with abundant eosinophilic cytoplasm with polyhedral cytoplasmic limits without cyto-nuclear atypia (Figure 1).

Presence of some spindle-shaped and clear cells producing pseudo cysts in place. The stroma is myxoid, dotted with a few mononuclear inflammatory elements, essentially lymphocytes (Figure 1).

An immunohistochemical study was carried out showing a positive labeling for the following antibodies: PS100; Cytokeratin AE1/AE3; and GFAP (Glial fibrillary acidic protein) (Figure 2).

Following this morphological aspect and this immunohistochemical profile, the diagnosis of a plasmocytoid (hyaline) myoepithelioma was retained. 


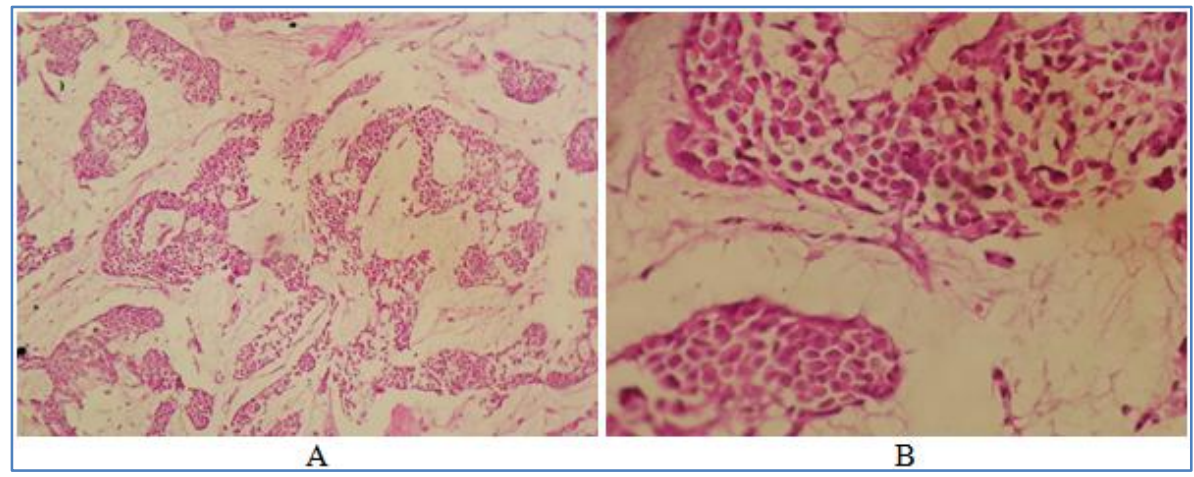

Fig-1: Proliferation of plasmacytoid cells within a myxoid stroma at low (A : HE x100) and at medium magnification (B : HE $\mathbf{x 2 0 0 )}$

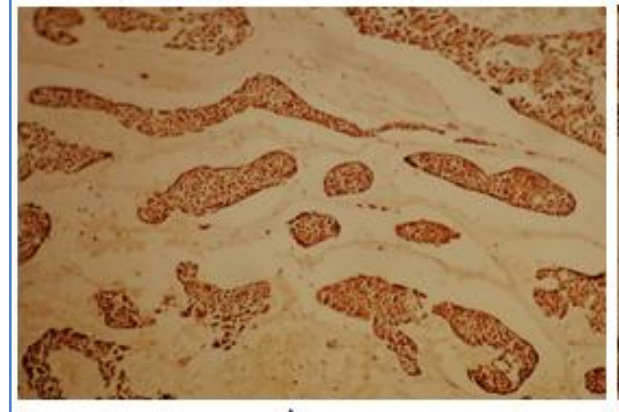

A

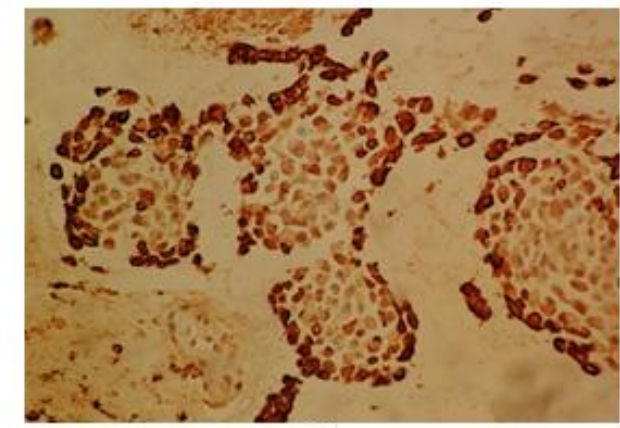

$\mathrm{C}$

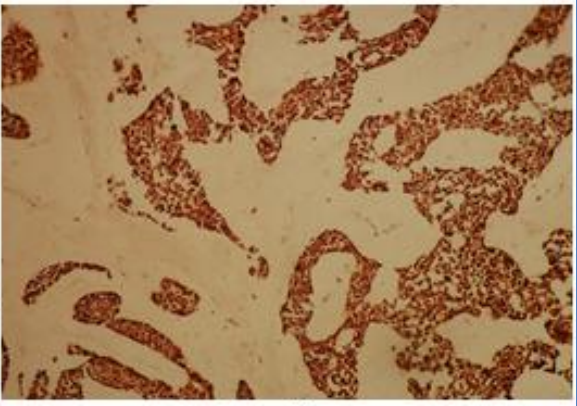

B

Fig-2: Immunohistochemical study: positive labeling of tumor cells by PS 100 (A) ; GFAP (B) et CK AE1-AE3 (C)

\section{DISCUSSION}

The term myoepithelioma was first used by Sheldon in 1943 [3], but the tumor was reclassified as an independent entity in 1991 by the World Health Organization during the international classification of gland tumors salivaries [4]. Myoepithelioma occurs in men and women equally, the average age varies between 30 and 40 years, but it can be observed on a very wide average age ranging from children to the elderly [5]. Like pleomorphic adenoma, myoepithelioma frequently appears in the parotid gland (40\% of cases), followed by the palatal glands (approximately 21\%). Clinically this tumor usually presents as a painless, slow growing and insidious swelling. There are no signs of nerve damage or lymphadenopathy [6]. Myoepithelioma of the lip is extremely rare and appears in the form of a solid tumor with a peripheral border; the center of the lesion is white to yellowish-white in appearance. Sometimes it takes on a semi-translucent or myxoid appearance when the extracellular matrix is abundant.
Two questions arise, the answer to which is far from easy. One is academic: is it a myoepithelioma? The other is practical, and therapeutic monitoring depends on it: is it a benign tumor, distinct from myoepithelial carcinoma or any other variety of salivary cancer with myoepithelial cells? Before discussing these two points, the conditions of the diagnosis must be recalled. As is usually the case for tumors of the salivary glands, it is on the piece of excision that the diagnosis is made (and was in our patient): the biopsy is not contributory in myoepitheliomas in because of the variability of their structure from one territory to another, from one lesion to another,and the existence of a sometimes very abundant myoepithelial population [10].

Histologically, myoepithelioma is usually surrounded by a fibrous membrane, but when it is a minor salivary gland, this capsule becomes incomplete. The histological profile of myoepitheliomas changes 
according to the morphological variations known in myoepithelial neoplasias, whether in terms of tissue architecture or the type of majority cells [7, 8]. According to Dardick et al. [9], the epithelial cells represent $45 \%$ of the morphology of the tumor, followed, in order, by the spindle cells, then the plasmacytoid cells.

In the accessory salivary glands, the cells are rather plasmocytoid [11]. However, the myoepithelial nature suggested by the morphology is confirmed by immunohistology [12, 10]: Positivity of PS-100, vimentin and GFAP (glial fibrillary acid protein). The coexistence of labeling for keratin and smooth muscle is of course the most convincing on the pathophysiological and histopathogenetic level. Besides myoepithelial cells, some authors consider that we can find epithelial cells forming ductal structures but which do not exceed $10 \%$ of the entire lesion [13, 10, 14]. Such structures were seen focal point in the current tumor. The differential diagnosis involves numerous salivary lesions containing myoepithelial cells. Among benign lesions, the closest to myoepithelioma is pleomorphic adenoma. As a result, myoepithelioma have long been classified by pathologists among these tumors $[12,15]$, of which they have the risk of recurrence, with however a lower probability [16]. The presence of a chondroid or myxoid stroma, however small and focal, identifies the pleomorphic adenoma. In addition to the benign form of myoepithelioma described above, the malignant form or myoepithelial carcinoma has also been identified.

This malignant form can occur "de novo", or appear secondarily on a benign myoepithelioma (the most frequent case) or on a pleomorphic adenoma [10]. Relatively rare, myoepithelial carcinoma represents less than $1 \%$ of malignant tumors of the salivary glands [17, 18]. The attack is generally later than the mild form (62 years on average), without predilection of sex [10]. Mainly parotid, it presents however one time on four in mucous seat and especially palatine.

It has the characteristics of a malignant tumor: absence of capsule, areas of necrosis [12, 19].

\section{CONCLUSION}

Myoepithelioma is a rare salivary tumor, especially in unusual locations causing diagnostic difficulties for the pathologist [20]. As for malignant myoepithelioma, knowledge of the disease and its pathological characteristics with precise use of immunohistochemistry is crucial $[20,21]$.

\section{REFERENCES}

1. Bonfils, P. (2007). Tumeur des glandes salivaires Encycl Med Chir (Paris) ORL 20_628_B_10.

2. Strick, M. J., Kelly, C., Soames, J. V., \& McLean, N. R. (2004). Malignant tumours of the minor salivary glands - a 20 year review. British journal of plastic surgery, 57(7), 624-631.

3. Sheldon, W.H. (1943). So-called mixed tumors of the salivary glands. Arch Pathol; 35:1e20.

4. Seifert, G., Sobin, L.H., eds. (1991). Histological Typing of Salivary Gland Tumours. World Health Organization International Histological Classification of Tumours, 2nd ed. Berlin: Springer-Verlag, 12.

5. Ellis, G. L. (1996). Tumors of the salivary glands. Atlas of tumor pathology, 3 .

6. Alos, L., Cardesa, A., Bombi, J. A., Mallofré, C., Cuchi, A., \& Traserra, J. (1996, May). Myoepithelial tumors of salivary glands: a clinicopathologic, immunohistochemical, ultrastructural, and flow-cytometric study. In Seminars in diagnostic pathology (Vol. 13, No. 2, pp. 138-147).

7. Ikuko, O. (2005). Atlas of Salivary Grand Tumors. Tokyo: Kanehara Shuppan, 51e6.

8. Takasi, S. (1999). Myoepithelioma. Clin Med Pathol; $17: 824 \mathrm{e} 5$

9. Dardick, I., Thomas, M. J., \& van Nostrand, A. P. (1989). Myoepithelioma-new concepts of histology and classification: a light and electron microscopic study. Ultrastructural pathology, 13(2-3), 187-224.

10. Alos, L., Cardesa, A., Bombi, J. A., Mallofré, C., Cuchi, A., \& Traserra, J. (1996, May). Myoepithelial tumors of salivary glands: a clinicopathologic, immunohistochemical, ultrastructural, and flow-cytometric study. In Seminars in diagnostic pathology, 13(2), 138147.

11. Taylor, J., \& Tighe, J. V. (1999). A minor salivary gland tumour presenting with dysphagia. The Journal of Laryngology \& Otology, 113(6), 569572.

12. Ellis, G. L. (1996). Tumors of the salivary glands. Atlas of tumor pathology, 3 .

13. Simpson, R. H. W., Jones, H., \& Beasley, P. (1995). Benign myoepithelioma of the salivary glands: a true entity?. Histopathology, 27(1), 1-9.

14. Dardick, I. (1995). Myoepithelioma: definitions and diagnostic criteria. Ultrastructural pathology, 19(5), 335-345.

15. Barnes, L., Appel, B. N., Perez, H., \& Moneim El- Attar, A. (1985). Myoepitheliomas of the head and neck: case report and review. Journal of surgical oncology, 28(1), 21-28.

16. Seifert, G., \& Sobin, L. H. (1992). The world health organization's histological classification of salivary gland tumors. A commentary on the second edition. Cancer, 70(2), 379-385.

17. Auclair, P. L., \& Ellis, G. L. (1996). Atypical features in salivary gland mixed tumors: their relationship to malignant transformation. Modern pathology: an official journal of the United States and Canadian Academy of Pathology, Inc, 9(6), 652-657. 
18. Savera, A. T., Sloman, A., Huvos, A. G., \& Klimstra, D. S. (2000). Myoepithelial carcinoma of the salivary glands: a clinicopathologic study of 25 patients. The American journal of surgical pathology, 24(6), 761-774.

19. Skalova, A., Michal, M., Ryška, A., Simpson, R. H., Kinkor, Z., Walter, J., \& Leivo, I. (1999). Oncocytic myoepithelioma and pleomorphic adenoma of the salivary glands. Virchows Archiv, 434(6), 537-546.
20. Gore, C. R., Panicker, N. K., Chandanwale, S. S., \& Singh, B. K. (2013). Myoepithelioma of minor salivary glands-A diagnostic challenge: Report of three cases with varied histomorphology. Journal of oral and maxillofacial pathology: JOMFP, 17(2), 257.

21. Wang, C., Zhang, Z., Ge, Y., Liu, Z., Sun, J., Gao, Z., \& Li, L. (2015). Myoepithelial carcinoma of the salivary glands: A clinicopathologic study of 29 patients. Journal of Oral and Maxillofacial Surgery, 73(10), 1938-1945. 